\title{
Polysulfones with Phenylalanine Derivatives as Chiral Selectors - Membranes for Chiral Separation
}

\author{
Jun Isezaki ${ }^{1}$, Masakazu Yoshikawa ${ }^{1, *}$, Nanwen $\mathrm{Li}^{2}$, Gilles P. Robertson ${ }^{3}$ and \\ Michael D. Guiver ${ }^{2,3}$
}

${ }^{1}$ Department of Biomolecular Engineering, Kyoto Institute of Technology, Matsugasaki, Kyoto 606-8585, Japan

${ }^{2}$ Department of Energy Engineering, Hanyang University, Seoul 133-791, Republic of Korea

${ }^{3}$ Institute for Chemical Process and Environmental Technology, National Research Council of Canada, Ottawa, Ontario K1A OR6, Canada

\begin{abstract}
Polysulfone with a derivative of phenylalanyl residue as a chiral selector (PSf-Ac-D-Phe or PSf-Ac-L-Phe) were prepared by polymer reaction of benzylamine-modified polysulfones with $\mathrm{N}$ - $\alpha$-acetyl-D-phenylalanine or $\mathrm{N}$ - $\alpha$-acetylL-phenylalanine. Both polysulfones having a chiral selector gave durable self-standing membranes. The specific rotations of those polymers revealed that the chiral selectors were successfully introduced into the polysulfone. PSf-AcD-Phe membrane incorporated L-Glu in preference to D-Glu and vice versa. The chiral separation ability was studied by applying a concentration gradient as a driving force for membrane transport. Permselectivities for those two types of membrane reflected their adsorption selectivities. PSf-Ac-D-Phe membrane selectively transported L-Glu and vice versa. Predicted permselectivities by adopting membrane resistance coincided with the observed ones.
\end{abstract}

Keywords: Chiral separation, membrane, optical resolution, permselectivity, polysulfone.

\section{INTRODUCTION}

Membrane separation is perceived to economically and ecologically competitive to other conventional separation methods since membrane separations, excepting pervaporation, are operated without phase transition. In addition to this, membrane separation is continuously operated under mild conditions. So far, membrane separation has been applied in various fields, such as water purification by reverse osmosis (RO), production of ultrapure water by nanofiltration (NF), waste water treatment by microfiltration (MF) or ultrafiltration (UF), concentration and recovery of valuable substrates by MF or UF, concentration or removal of charged materials by electrodialysis (ED), gas separation for recovery of $\mathrm{H}_{2}$, for concentration of $\mathrm{O}_{2}$, and for removal of $\mathrm{CO}_{2}$, hemodialysis, hemofiltration, and so forth. However, chiral separation has not been practically carried out by membrane separation technique. The demand for chiral separation by membrane has been required in industries, involving pharmaceuticals, agrochemicals, food additives, perfumes, and so forth. In chiral separation, excepting optical activity, the target enantiomer and the antipode show same physical and chemical properties under achiral environment [1-3]. From this, the existence of

*Address corresponding to this author at the Department of Biomolecular Engineering, Kyoto Institute of Technology, Matsugasaki, Kyoto 606-8585, Japan; Tel: +81-75-724-7816; Fax: +81-75-724-7800;

E-mail: masahiro@kit.ac.jp

NRCC Publication No. 53124. chiral environment or chiral recognition site is requisite in membrane or membrane separation system so that chiral separation can be achieved by using membrane [4-7].

The authors' research group studied polymeric membranes having molecular recognition sites introduced by applying an alternative molecular imprinting [8-11] and those with chiral environment in a main chain $[12,13]$ or in a side chain [14] for chiral separation. As a side chain, alanyl derivatives were attached onto polysulfone via amide linkage. Among amino acids, there are 38 kinds of amino acid residue, which are expected to work as chiral environments or chiral selectors. In the present study, the authors focused their attentions on phenylalanine derivatives. Phenylalanine, containing benzyl moiety as a side chain of amino acid, was adopted as chiral selector in the present study. Phenylalanine has a larger and a more hydrophobic side chain, which might effectively exhibit chiral recognition ability, compared with alanine. To this end, $\mathrm{N}$ - $\alpha$-acetyl-D-phenylalanine (Ac-D-Ala-OH) or $\mathrm{N}$ - $\alpha$-acetyl-L-phenylalanine (Ac-L-Ala-OH) was adopted as a candidate for a chiral selector and each of those was introduced into polysulfone with benzylamine group (PSf- $\mathrm{NH}_{2}$ ) by polymer reaction. Chiral separation ability, such as adsorption selectivity and permslectivity, for those membranes were studied adopting racemic mixture of Glu as model racemates. In addition to these, a facile way to evaluate chiral separation ability of those membranes will be proposed 
by measuring membrane resistance of each enantiomer/membrane system.

\section{EXPERIMENTAL}

\section{Materials}

Polysulfone bearing benzylamine group (PSf- $\left.\mathrm{NH}_{2}\right)$ with a degree of substitution (DS) of 0.95 was prepared by the modification of polysulfone Udel P-3500 as reported previously [15]. Following similar procedures for the previous study [15], commercial polysulfone was lithiated with $1.0 \mathrm{~mol}$ equivalent of butyllithium, quenched with benzonitrile, then reduced with sodium borohydride to give PSf- $\mathrm{NH}_{2}$ with DS of 0.95 . $\mathrm{N}-\alpha-$ Acetyl-D-phenylalanine (Ac-D-Phe-OH) and $\mathrm{N}$ - $\alpha$-acetylL-phenylalanine (Ac-L-Phe-OH) were purchased from Watanabe Chemical Industries Ltd. (Hiroshima, Japan) and used without purification. N-(3-Dimethylaminopropyl)-N'-ethytlcarbodiimide hydrochloride (WSCD/HCl) and 1-hydroxybenzotriazole (HOBt) were purchased from Peptide Institute Inc. (Osaka, Japan) and used without further purification. N,NDimethylformamide (DMF) was purified by conventional method [16]. Ethanol, dimethylsulfoxide (DMSO), Dglutamic acid (D-GLu), and L-glutamic acid (L-GLu) were obtained from commercial sources and used as received. Water purified with an ultrapure water system (Simpli Lab. Millipore S. A., Molsheim, France) was used.

\section{Synthesis of the Membrane Materials}

As shown in Figure 1, a $15.0 \mathrm{~cm}^{3}$ DMF solution containing requisite amounts of $\mathrm{PSf}-\mathrm{NH}_{2}$, Ac-Phe-OH (Ac-D-Phe-OH or Ac-L-Phe-OH), WSCD/HCl, and HOBt was stirred at $40^{\circ} \mathrm{C}$ for 2 weeks. After the reaction, the reaction mixture was poured into ethanol and the prescribed product was washed with ethanol and dried in vacuo. A $1.15 \mathrm{~g}$ (96.6\%) of the modified polysulfone with AC-D-Phe as a chiral selector, PSf-Ac-D-Phe, was obtained, while the yield of PSf-Ac-L-Phe was $1.18 \mathrm{~g}$ (98.3\%).

\section{Characterization of Membrane Materials}

The Fourier-transform infrared (FTIR) spectra of DMSO-cast membranes were recorded by using Perkin-Elmer Spectrum GX; 64 scans at a resolution of $4 \mathrm{~cm}^{-1}$.

The ${ }^{1} \mathrm{H}$ NMR spectra $(300 \mathrm{MHz})$ were recorded in DMSO- $_{6}$ using a BRUKER AV-300 and the solvent signal (2.50 ppm [17]) was as an internal standard.

The thermal stability of the modified polymer was evaluated on a Hi-Res Modulated TGA 2950 (TA instruments) under nitrogen at a heating rate of $5.0^{\circ} \mathrm{C}$ $\min ^{-1}$.

Dynamic mechanical thermal analysis (DMTA) measurement was carried out with a dynamic analyzer, RSA III (TA Instruments, Inc.) in tension mode. The experiment was performed at a frequency of $1 \mathrm{~Hz}$ and a heating rate of $2.0^{\circ} \mathrm{C} \mathrm{min}{ }^{-1}$ from $80^{\circ} \mathrm{C}$ to $140{ }^{\circ} \mathrm{C}$ for PSf-AC-D-Phe and from $80^{\circ} \mathrm{C}$ to $120^{\circ} \mathrm{C}$ for PSf-AC-LPhe. The dimension of sample was $20.01 \times 6.00 \times 0.11$ $\mathrm{mm}^{3}$.

The specific rotations were obtained with Horiba SEPA-200 Polarimeter at $589 \mathrm{~nm}$ at ambient temperature in DMF.

\section{Membrane Preparation}

A $0.30 \mathrm{~g}$ of polymer was dissolved in $3.0 \mathrm{~cm}^{3}$ of DMF. The polymer solution was poured into a flat laboratory dish (11.6 $\mathrm{cm}$ diameter) and the solvent was allowed to be evaporated at $50{ }^{\circ} \mathrm{C}$ for $2 \mathrm{~d}$. The thickness of PSf-Ac-D-Phe membrane determined by micrometer was $48 \mu \mathrm{m}$ and that of PSf-Ac-L-Phe one being $40 \mu \mathrm{m}$.
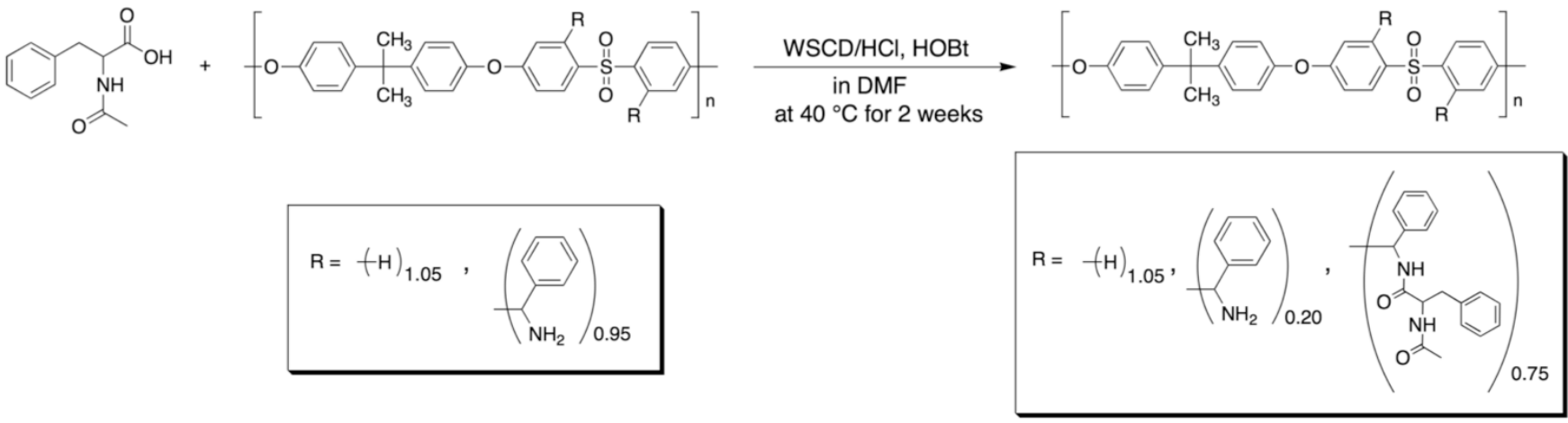

Figure 1: Synthetic scheme of polysulfones with phenylalanyl residue as a chiral selector. 


\section{Adsorption Selectivity}

The membranes were immersed in an aqueous solution of racemic Glu (each enantiomeric Glu was 1.0 $\times 10^{-3} \mathrm{~mol} \mathrm{dm}^{-3}$ ), and the membranes were allowed to be equilibrated at $40{ }^{\circ} \mathrm{C}$. A 0.02 wt.- $\%$ of sodium azide was added as a fungicide. Aliquots of the solution at the initial stage and after equilibrium had been reached were used for quantitative estimation by liquid chromatography (LC) [Jasco PU1580, equipped with a UV detector (Jasco UV1570)] employing Chiralpak $\mathrm{MA}(+)$ column [50 x 4.6 (i.d.), Daicel Chemical Ind.]. An aqueous copper sulfate solution was used as a mobile phase.

The amount of Glu in the supernatant subtracted from the initial amount in the solution gave the amount of Glu adsorbed by the membrane. The adsorption selectivity $S_{\mathrm{A}(\mathrm{i} j)}$ is defined as:

$S_{\mathrm{A}(\mathrm{i} j)}=((\mathrm{i}-\mathrm{Glu}) /(\mathrm{j}-\mathrm{Glu})) /([\mathrm{i}-\mathrm{Glu}] /[\mathrm{j}-\mathrm{Glu}])$

where (i-Glu) and [i-Glu] are the amount of Glu adsorbed in the membrane and the concentration in the solution after equilibrium had been reached. Hereafter, subscripts of $D$ and $L$ mean the $D$ - and the L-isomer, respectively.

\section{Enantioselective Transport}

A membrane $\left(3.0 \mathrm{~cm}^{2}\right)$ was fixed tightly with Parafilm between two chambers of a permeation cell. The volume of each chamber was $40.0 \mathrm{~cm}^{3}$. An aqueous solution of racemic Glu was placed in the leftside chamber ( $L$-side) and an aqueous solution in the right-side chamber (R-side). Each concentration of racemic Glu was fixed to be $1.0 \times 10^{-3} \mathrm{~mol} \mathrm{dm}^{-3}$. In both chambers, 0.02 wt.- $\%$ of sodium azide was added as a fungicide. All experiments were carried out at $40{ }^{\circ} \mathrm{C}$ with stirring. An aliquot was drawn from the permeate side (R-side) at each sampling time. The amounts of $D$ and L-isomers that transported through the membrane were determined by LC as described above.

The flux, $J\left(\mathrm{~mol} \mathrm{~cm}^{-2} \mathrm{~h}^{-1}\right)$, is defined as:

$J=Q / A t$

where $Q(\mathrm{~mol})$ is the amount of transported Glu, $A$ $\left(\mathrm{cm}^{2}\right)$ the effective membrane area, and $t(\mathrm{~h})$ is the time.

The permselectivity $\alpha_{i j}$ is defined as the flux ratio $J_{\mathrm{i}} / J_{\mathrm{j}}$ divided by the concentration ratio [i-Glu]/[j-Glu]

$\alpha_{\mathrm{i} / \mathrm{j}}=\left(\mathrm{J}_{\mathrm{i}} / J_{\mathrm{j}}\right) /([\mathrm{i}-\mathrm{Glu}] /[\mathrm{j}-\mathrm{Glu}])$

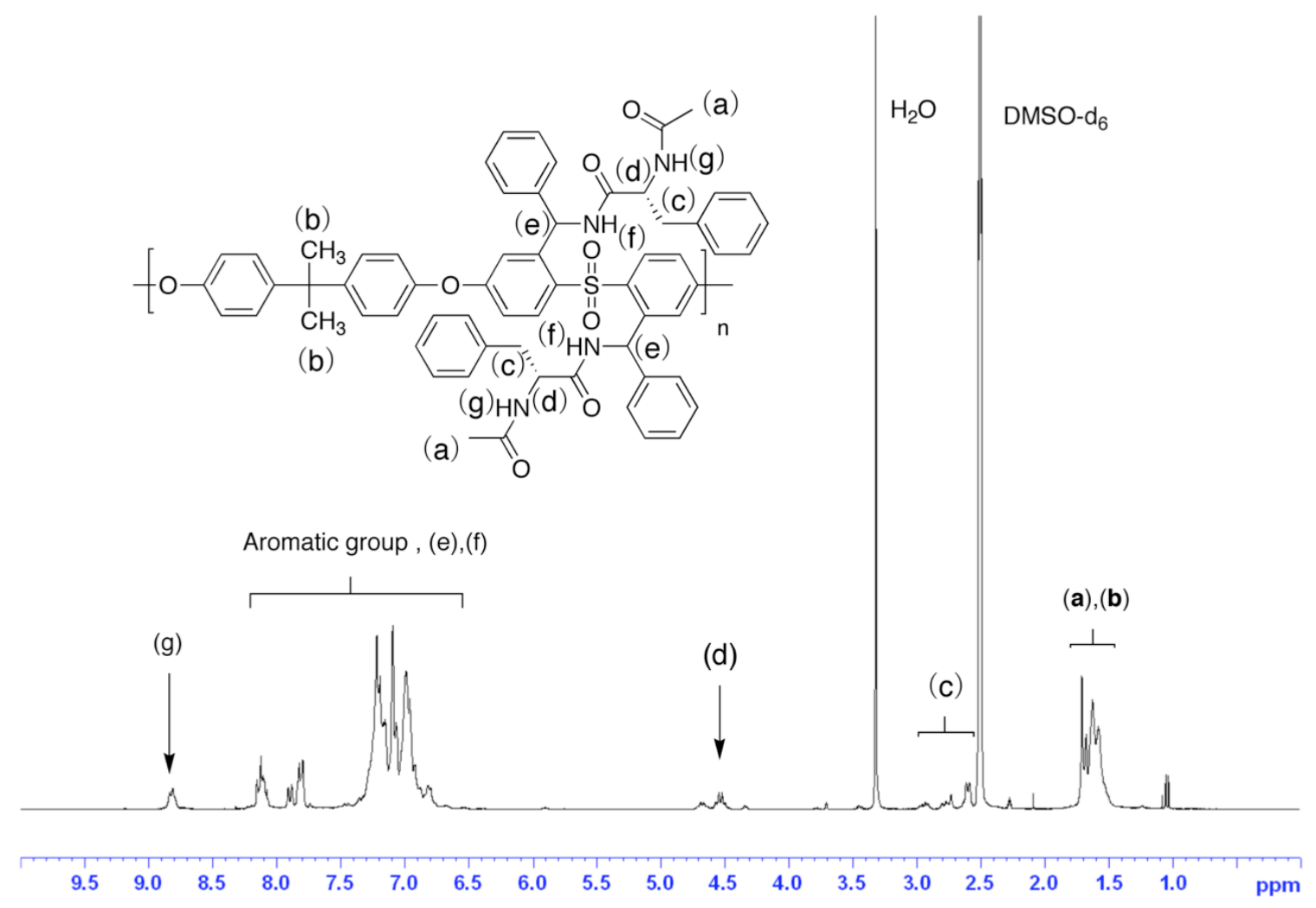

Figure 2: ${ }^{1} \mathrm{H}$ NMR spectrum of PSf-Ac-D-Phe. ( $300 \mathrm{MHz}$; DMSO-d $\mathrm{d}_{6}$. 
Table 1: Results for Introduction of Chiral Selector onto Polysulfone

\begin{tabular}{|c|c|c|c|c|c|c|c|}
\hline & $\begin{array}{c}\text { PSf-NH } \\
\mathbf{g} \\
\text { (mol) }\end{array}$ & $\begin{array}{c}\text { Ac-D-Phe-OH } \\
\text { g } \\
(\mathrm{mol})\end{array}$ & $\begin{array}{c}\text { Ac-L-Phe-OH } \\
\text { g } \\
\text { (mol) }\end{array}$ & $\begin{array}{c}\text { WSCD/HCl } \\
\underset{(\mathrm{mol})}{\mathrm{g}}\end{array}$ & $\begin{array}{c}\mathrm{HOBt} \\
\mathbf{g} \\
(\mathrm{mol})\end{array}$ & $\begin{array}{c}\text { Yield } \\
\mathbf{g} \\
(\%)\end{array}$ & $\begin{array}{l}\mathrm{DS}^{\mathrm{a}} \\
(\%)^{\mathrm{b}}\end{array}$ \\
\hline PSf-Ac-D-Phe & $\begin{array}{c}1.02 \\
\left(1.89 \times 10^{-3}\right)^{\mathrm{c}}\end{array}$ & $\begin{array}{c}1.09 \\
\left(5.26 \times 10^{-3}\right)\end{array}$ & $\begin{array}{l}- \\
(-)\end{array}$ & $\begin{array}{c}1.09 \\
\left(5.68 \times 10^{-3}\right)\end{array}$ & $\begin{array}{c}0.77 \\
\left(5.70 \times 10^{-3}\right)\end{array}$ & $\begin{array}{c}1.15 \\
(96.6)\end{array}$ & $\begin{array}{r}0.75 \\
(79.0)\end{array}$ \\
\hline PSf-Ac-L-Phe & $\begin{array}{c}1.03 \\
\left(1.90 \times 10^{-3}\right)^{c}\end{array}$ & $\begin{array}{l}- \\
(-)\end{array}$ & $\begin{array}{c}1.19 \\
\left(5.74 \times 10^{-3}\right)\end{array}$ & $\begin{array}{c}1.10 \\
\left(5.74 \times 10^{-3}\right)\end{array}$ & $\begin{array}{c}0.78 \\
\left(5.77 \times 10^{-3}\right)\end{array}$ & $\begin{array}{c}1.18 \\
(98.3)\end{array}$ & $\begin{array}{r}0.75 \\
(79.0)\end{array}$ \\
\hline
\end{tabular}

${ }^{\mathrm{a}}$ Degree of substitution.

b $(D S / 0.95) \times 100$

${ }^{c}$ Mole number of constitutional repeating unit (CRU) of PSf- $\mathrm{NH}_{2}$.

\section{Membrane Conductance (Membrane Resistance)}

Membrane conductance was estimated from membrane resistance. The resistances of each D-Glu or L-Glu solution with membrane and without membrane were measured by using Portable Kohlrausch Bridge TYPE BF-62A (Shimadzu Rika Instruments Co., Ltd.) and CO-1305 oscilloscope (KENWOOD). The area of each platinum electrode was $1.0 \mathrm{~cm}^{2}$ and the distance between the electrodes was fixed to be $7.0 \mathrm{~cm}$. An aqueous solution of optically pure D-Glu or L-Glu, of which concentration being $1.0 \mathrm{x}$ $10^{-3} \mathrm{~mol} \mathrm{dm}^{-3}$, was poured into both chambers (R-side and $\mathrm{L}$-side). The resistance was measured at a constant temperature of $40{ }^{\circ} \mathrm{C}$ with stirring. The measurement of resistance was completed within a few minutes.

\section{RESULTS AND DISCUSSION}

\section{Polysulfones with Phenylalanine Derivative}

In the IR spectra, the amide I bands were observed at $1656 \mathrm{~cm}^{-1}$. The ${ }^{1} \mathrm{H}$ NMR spectrum of PSf-Ac-D-Phe is shown in Figure 2, which was similar to the one observed for PSf-Ac-L-Phe. From ${ }^{1} \mathrm{H}$ NMR spectra, $79.0 \%$ of PSf- $\mathrm{NH}_{2}$ amino groups were concluded to have reacted with both $\mathrm{Ac}-\mathrm{D}-\mathrm{Phe}-\mathrm{OH}$ and $\mathrm{Ac}-\mathrm{L}-\mathrm{Phe}-\mathrm{OH}$ by using the area of amide proton ( $\mathrm{g}$ ) and methyl proton (a) and (b). From above, the degree of substitution (DS) for the phenylalanyl moiety in both PSf-Ac-D-Phe and PSf-Ac-L-Phe was determined to be 0.75 . The results are summarized in Table 1 together with reaction conditions.

\section{Thermal Properties}

Figure 3 shows thermogravimetric analysis (TGA) thermographs for PSf-AC-D-Phe and PSf-AC-L-Phe. Comparing with thermal stabilities of analogous polymers, PSf-Ac-Ala's [18], which had $\mathrm{N}-\alpha$ acetylalanine derivative instead of Ac-Phe as a chiral selector, the degradation temperature, $T_{d}$, for the present polymers were slightly lower than that for PSfAc-Ala ( $T_{d}$ for PSf-Ac-D-Ala, $306{ }^{\circ} \mathrm{C} ; T_{d}$ for PSf-Ac-LAla, $307{ }^{\circ} \mathrm{C}$ [18]). This led to the conclusion that the side group of Phe residue was more flexible than that

(b) PSf-Ac-L-Phe

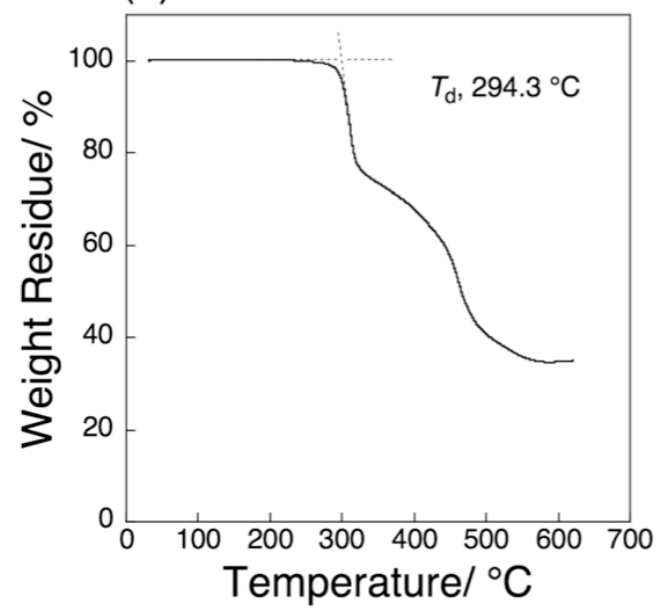

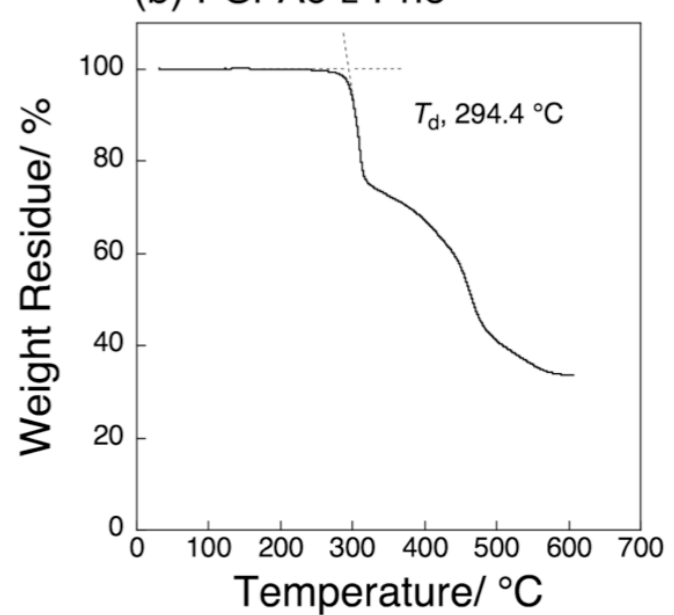

Figure 3: TGA curves of PSf-Ac-D-Phe (a) and PSf-Ac-L-Phe (b). (Heating rate, $5.0^{\circ} \mathrm{C} \mathrm{min}^{-1}$ ). 
(a) PSf-Ac-D-Phe

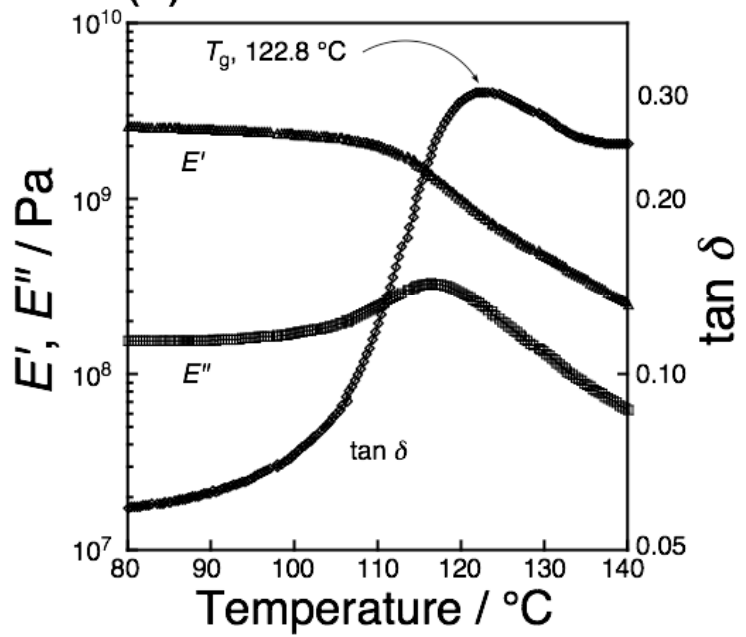

(b) PSf-Ac-L-Phe

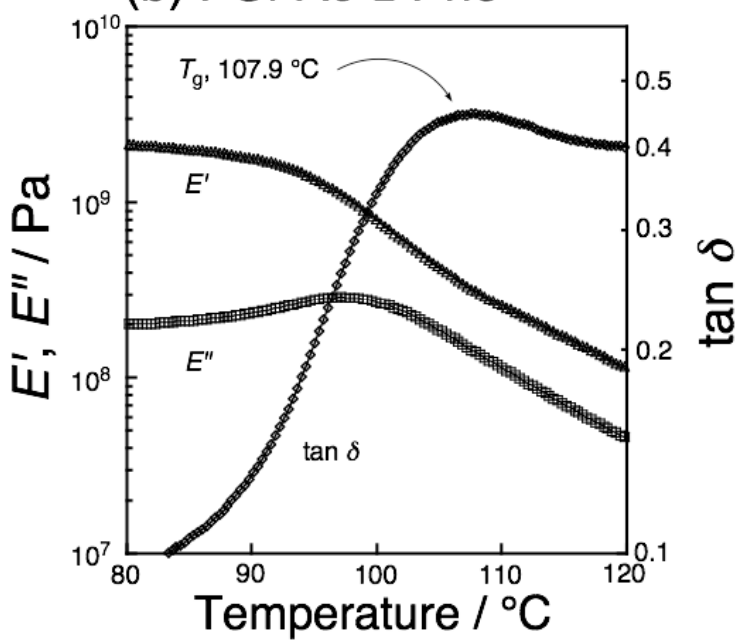

Figure 4: Temperature dependence of $E^{\prime}, E^{\prime \prime}$, and tan $\delta$ for PSf-Ac-D-Phe (a) and PSF-Ac-L-Phe (b) at a frequency of $1 \mathrm{~Hz}$ and a heating rate of $2.0^{\circ} \mathrm{C} \mathrm{min}^{-1}$.

in Ala residue in the present study. This conclusion will be closely correlated to the following glass transition temperature.

Figure 4 shows the dependence of dynamic storage modulus $E^{\prime}$, dynamic loss modulus $E^{\prime \prime}$, and $\tan \delta$ on temperature for those two types of polymer. The peak on $\tan \delta$, assigned to the glass transition temperature $T_{\mathrm{g}}$, can be found at $122.8{ }^{\circ} \mathrm{C}$ for PSf-Ac-D-Phe and $107.9{ }^{\circ} \mathrm{C}$ for PSf-Ac-L-Phe, respectively. The $T_{\mathrm{g}}$ 's for PSf-Ac-Ala's were higher than those for PSf-Ac-Phe's and over $190{ }^{\circ} \mathrm{C}$ [18]. $T_{\mathrm{g}}$ 's were observed to decrease with the enlargement of side group of amino acid residue. In the present study, $T_{\mathrm{g}}$ values are more dependent on the flexibility, rather than the size of the amino acid residue, which causes steric hindrance [19]. Even though two types of PSf-Ac-Phe polymer have similar DS of 0.75 , PSf-Ac-D-Phe gave around $15^{\circ} \mathrm{C}$ higher $T_{\mathrm{g}}$ than PSf-Ac-L-Phe. The micro structure of the polymer, in other words, the way of attachment of Phe moiety via amide linkage for the former and that for the latter might be a little bit different, though, at the moment, there are no definite experimental results to explain the difference in observed $T_{\mathrm{g}}$.

\section{Chiroptical Properties}

The optical rotations $\left([\alpha]_{\mathrm{D}}\right)$ of the polysulfone with chiral selector Phe are summarized in Table 2 together with those for the starting chiral building blocks. The optical rotations for PSf-AC-D-Phe were opposite to that for PSf-Ac-L-Phe. The results in Table 2 revealed that optically active polymers were successfully obtained via polymer reaction between $\mathrm{PSf}-\mathrm{NH}_{2}$ and phenylalanine derivative.
Table 2: Specific Rotations of PSf-Ac-Phe and their Chiral Building Blocks

\begin{tabular}{|c|c|}
\hline & {$[\alpha]_{\mathrm{D}}{ }^{*}$} \\
\cline { 2 - 2 } & $\operatorname{deg} \mathbf{~ c m}^{2} \mathbf{~ g}^{-1}$ \\
\hline \hline PSf-Ac-D-Phe & -0.54 \\
\hline PSf-Ac-L-Phe & 0.49 \\
\hline Ac-D-Phe-OH & -3.80 \\
\hline Ac-L-Phe-OH & 3.75 \\
\hline
\end{tabular}

${ }^{*}$ In DMF; $c=1.0 \mathrm{~g} \mathrm{dL}^{-1} ; \mathrm{L}=10 \mathrm{~cm}$.

\section{Adsorption Selectivity}

Adsorption selectivity of the present membranes toward racemic mixture of Glu was studied. The results of adsorption study are summarized in Table 3. PSf-AcD-Phe membrane adsorbed L-Glu in preference to the D-isomer of Glu and vice versa. The adsorption selectivity of PSf-AC-D-Phe membrane toward L-Glu was determined to be 1.39 , while that of PSf-Ac-L-Phe one toward the $\mathrm{D}$-isomer to be 1.33. In the previous study, PSf-Ac-Ala membranes showed opposite adsorption selectivity $[14,18]$. This might be due to the difference in amino acid residue attached as a chiral selector. From above results, those membranes can be expected to exhibit chiral separation ability of racemic mixture, which will be confirmed in the next section.

\section{Chiral Separation}

Chiral separation ability of the present membranes was studied by adopting racemic mixture of Glu as model racemates. In the present study, concentration gradient was adopted as a driving force for membrane transport. Time-transport curves of racemic mixture of 
Table 3: Adsorption Selevtivity of PSf-Ac-Phe Membranes

\begin{tabular}{|c|c|c|c|c|c|c|}
\hline \multirow{3}{*}{ Membrane } & \multicolumn{2}{|c|}{ D-Glu } & \multicolumn{2}{|c|}{ L-Glu } & \multirow{3}{*}{$S_{A(D / L)}$} & \multirow{3}{*}{$S_{A(L / D)}$} \\
\hline & (D-Glu)/mem. & \multirow{2}{*}{$(\mathrm{D}-\mathrm{Glu}) /(\mathrm{CRU})^{*}$} & (L-Glu)/mem. & \multirow{2}{*}{$(\mathrm{L}-\mathrm{Glu}) /(\mathrm{CRU})^{*}$} & & \\
\hline & mol/g-mem. & & mol/g-mem. & & & \\
\hline PSf-Ac-D-Phe & $3.44 \times 10^{-6}$ & $2.30 \times 10^{-3}$ & $4.78 \times 10^{-6}$ & $3.20 \times 10^{-3}$ & 0.72 & 1.39 \\
\hline PSf-Ac-L-Phe & $4.93 \times 10^{-7}$ & $3.29 \times 10^{-4}$ & $3.69 \times 10^{-7}$ & $2.47 \times 10^{-4}$ & 1.33 & 0.75 \\
\hline
\end{tabular}

${ }^{*}$ Mole number for constitutional repeting unit (CRU) of PSf-Ac-Phe.

Glu through those membranes are shown in Figure 5. As can be seen, permselectivities for those membranes toward racemic mixture of Glu reflected their adsorption selectivities. In other words, PSf-Ac-D-Phe membrane selectively transported L-Glu, which was preferentially incorporated into it, and vice versa.

From the steady-state part of time-transport curves, both fluxes, which were adopted to determine permselectivity as described above, and apparent timelag can be determined. Following solution-diffusion model $[20,21]$, diffusivity selectivity, which is a ratio of diffusion coefficients of $\mathrm{i}$ - and j-isomer, $S_{\mathrm{D}(\mathrm{i} j)}\left(=D_{\mathrm{i}} / D_{\mathrm{j}} ; D_{\mathrm{i}}\right.$ and $D_{\mathrm{i}}$ are the diffusion coefficients of $\mathrm{i}$ - and j-isomer, respectively), can be determined by equation (4), using permselectivity and adsorption selectivity.

$S_{\mathrm{D}(i j)}=\alpha_{i j j} / S_{A(i j)}$

Apparent diffusivity selectivity can be also determined by equation (5), using apparent time-lag.

$S_{\mathrm{D}(i j)}=\theta_{\mathrm{J}} / \theta_{1}$

where $\theta_{1}$ and $\theta_{1}$ are the apparent time lag of $\mathrm{i}-$ and $\mathrm{j}$ isomer, respectively. Diffusivity selectivities determined

(a) PSf-Ac-D-Phe

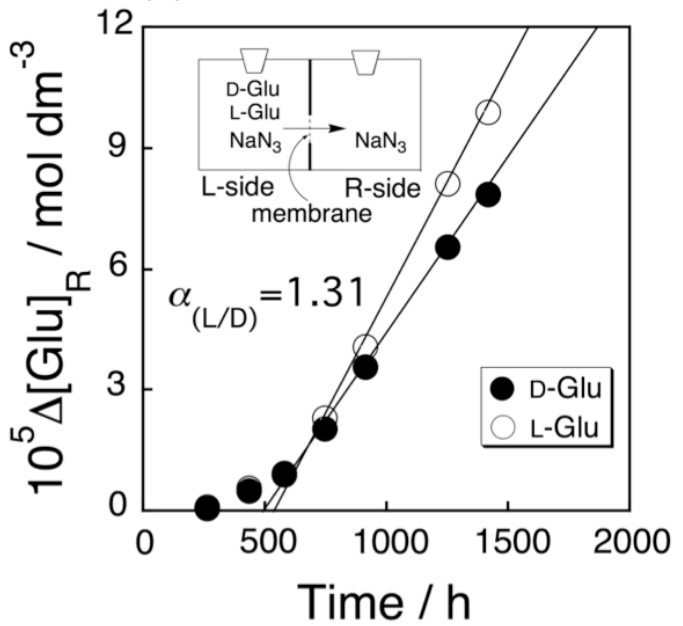

by both methods are summarized in Table 4 . As can be seen, diffusivity selectivity determined by permselectivity and adsorption selectivity coincides with apparent diffusivity selectivity estimated by timelag data.

In the present study, diffusivity selectivity is preferable to less adsorbed enantiomer as often observed in chiral separation $[8,11,13,22-27]$. The diffusion of enantiomer selectively adsorbed into the membrane was retarded by a relatively strong interaction between the enantiomer and the membrane. As a result, the antipode was diffused within the membrane faster than the enantiomer preferentially incorporated into the membrane. If the interaction between the enantiomer selectively adsorbed and the membrane was strong, permselectivity would be hardly expressed or the corresponding antipode would be selectively transported.

\section{Prediction of Permselectivity by Membrane Resistance}

As can be seen in Figure 5, in general, it takes a long time to study membrane transport phenomena. In

(b) PSf-Ac-L-Phe

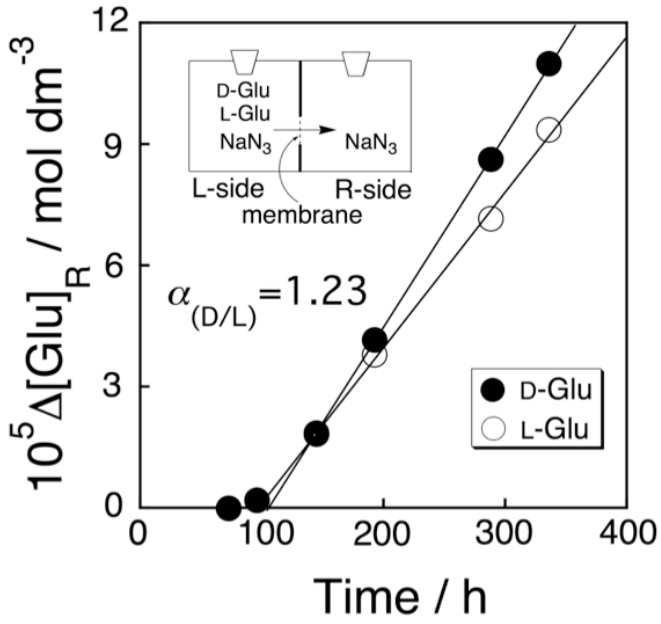

Figure 5: Time-transport curves of racemic mixture of Glu through PSf-Ac-D-Phe (a) and PSf-Ac-L-Phe (b) membranes at $40{ }^{\circ} \mathrm{C}$ adopting a concentration gradient as a driving force for membrane transport. 
Table 4: Summary of Membrane Transport

\begin{tabular}{|c|c|c|c|c|c|c|}
\hline Membrane & $\theta_{\mathrm{D}} / \mathbf{h}$ & $\theta_{\mathrm{L}} / \mathbf{h}$ & $\theta_{\mathrm{L}} / \theta_{\mathrm{D}}\left(=S_{\mathrm{D}(\mathrm{D} / \mathrm{L})}\right)^{\mathrm{a}}$ & $\theta_{\mathrm{D}} / \theta_{\mathrm{L}}\left(=S_{\mathrm{D}(\mathrm{L} / \mathrm{D})}\right)^{a}$ & $S_{D(D / L)}^{b}$ & $S_{D(L / D)^{c}}$ \\
\hline PSf-Ac-L-Phe & 105 & 95 & 0.90 & 1.11 & 0.92 & 1.09 \\
\hline
\end{tabular}

${ }^{\text {a } D e t e r m i n e d ~ f r o m ~ t i m e ~ l a g . ~}$

${ }^{b}$ Determined from permselectivity and adsorption selectivity; $S_{\mathrm{D}(\mathrm{D} / \mathrm{L})}=\alpha_{\mathrm{D} / \mathrm{L}} / S_{\mathrm{A}(\mathrm{D} / \mathrm{L})}$.

${ }^{c}$ Determined from permselectivity and adsorption selectivity; $S_{\mathrm{D}(\mathrm{L} / \mathrm{D})}=\alpha_{\mathrm{L} / \mathrm{D}} / S_{\mathrm{A}(\mathrm{L} / \mathrm{D})}$.

Table 5: Conductance and Membrane Performance

\begin{tabular}{|c|c|c|c|c|c|c|}
\hline & $\mathbf{1 0 ^ { - 3 }} \boldsymbol{R}_{\mathrm{D}} / \boldsymbol{\Omega}$ & $\mathbf{1 0 ^ { - 3 }} \boldsymbol{R}_{\mathrm{L}} / \boldsymbol{\Omega}$ & $\boldsymbol{G}_{\mathrm{D}} / \mathbf{G}_{\mathrm{L}}{ }^{\mathrm{a}}$ & $\boldsymbol{G}_{\mathrm{L}} / \boldsymbol{G}_{\mathrm{D}}{ }^{\mathrm{b}}$ & $\alpha_{\mathrm{D} / \mathrm{L}}$ & $\alpha_{\mathrm{L} / \mathrm{D}}$ \\
\hline \hline PSf-Ac-D-Phe & 3.80 & 2.90 & 0.76 & 1.31 & 0.76 & 1.31 \\
\hline PSf-AC-L-Phe & 5.53 & 6.79 & 1.23 & 0.81 & 1.23 & 0.81 \\
\hline
\end{tabular}

${ }^{\mathrm{a}} G_{\mathrm{D}} / G_{\mathrm{L}}=R_{\mathrm{L}} / R_{\mathrm{D}}$.

${ }^{\mathrm{b}} G_{\mathrm{L}} / G_{\mathrm{D}}=R_{\mathrm{D}} / R_{\mathrm{L}}$

the previous study [28], the authors' research group proposed that it was possible to predict the permselectivity of racemic mixture through a given membrane by measurements of membrane resistance for each enantiomer. The observed resistance $\left(R_{0 b s, i}\right)$ consists of that for solution $\left(R_{\mathrm{s}, \mathrm{i}}\right)$ and that for membrane $\left(R_{\mathrm{m}, \mathrm{i}}\right)$. The membrane resistances for each Glu for a given membrane were determined by the following equation:

$R_{\mathrm{m}, \mathrm{i}}=R_{\mathrm{obs}, \mathrm{i}}-R_{\mathrm{s}, \mathrm{i}}$

The determined membrane resistances for each enantiomer for each membrane are summarized in Table 5. The reciprocal of the membrane resistance is referred to as the membrane conductance. The ratio of the membrane conductance thus determined for each enantiomer will reflect permselectivity. The predicted permselectivity will be determined by the following equation:

$\alpha_{\mathrm{i} j}=G_{\mathrm{m}, \mathrm{l}} / G_{\mathrm{m}, \mathrm{j}}=\left(1 / R_{\mathrm{m}, \mathrm{i}}\right) /\left(1 / R_{\mathrm{m}, \mathrm{j}}\right)=R_{\mathrm{m}, \mathrm{j}} / R_{\mathrm{m}, \mathrm{i}}$

where $G_{m, i}$ means the membrane conductance for the enantiomer i-Glu and $R_{\mathrm{m}, \mathrm{i}}$ is the membrane resistance for i-Glu. The conductance ratios thus calculated and observed permselectivities are also given in Table $\mathbf{5}$ together with membrane resistances. From Table 5, as proposed in the previous study [28], the measurement of membrane resistance is a facile way to predict chiral separation ability.

In the present syudy, the membrane resistance was measured at one fixed concentration of $1.0 \times 10^{-3} \mathrm{~mol}$ $\mathrm{dm}^{-3}$, at which the performances for two types of membrane were studied. Concentrations of enantiomer, which were in contact with the membrane, had been changed, the transport mechanism, in some case, would have been deduced.

\section{CONCLUSIONS}

Polysulfone with a derivative of phenylalanyl residue as a chiral selector (PSf-Ac-D-Phe or PSf-Ac-L-Phe) were prepared by polymer reaction of benzylaminemodified polysulfones with $\mathrm{N}$ - $\alpha$-acetyl-D-phenylalanine or $\mathrm{N}-\alpha$-acetyl-L-phenylalanine. The specific rotations of those polymers revealed that the chiral selectors were successfully introduced into the polysulfone. Both polysulfones having a chiral selector gave durable selfstanding membranes. PSf-Ac-D-Phe membrane incorporated L-Glu in preference to D-Glu and vice versa. The chiral separation ability was studied by applying a concentration gradient as a driving force for membrane transport. Permselectivities for those two types of membrane reflected their adsorption selectivities. PSf-Ac-D-Phe membrane selectively transported L-Glu and vice versa. The permselectivity of PSf-AC-D-Phe membrane toward the L-Glu was determined to be 1.31 and that of PSf-AC-L-Phe one to be 1.23. Predicted permselectivities by adopting membrane resistance coincided with the observed ones.

\section{REFERENCES}

[1] Vollhardt KPC, Schore NE. Organic chemistry Structure and function. $3^{\text {rd }}$ ed. New York: W.H. Freeman and Company 1999.

[2] Voet D, Voet JG. Biochemistry. New York: Wiley 1990.

[3] McKee T, McKee JR, Biochemistry - The Molecular basis of life. 3rd ed. Boston: WCB/McGraw-Hill 2003.

[4] Afonso CAM, Crespo JG, Angew Chem Int Ed 2004; 43: 5293-5.

http://dx.doi.org/10.1002/anie.200460037 
[5] Maier NM, Linder W. Anal Bioanal Chem 2007; 389: 377-97. http://dx.doi.org/10.1007/s00216-007-1427-4

[6] Xie R, Chu L-Y, Deng JG. Chem Soc Rev 2008; 37: 1243-63. http://dx.doi.org/10.1039/b713350b

[7] Higuchi A, Tamai M, Ko Y-A, et al. Polym Rev 2010; 50: 11343.

http://dx.doi.org/10.1080/15583721003698853

[8] Yoshikawa M, Izumi J. Macromol Biosci 2003; 3: 487-98. http://dx.doi.org/10.1002/mabi.200350016

[9] Itou Y, Nakano M, Yoshikawa M. J Membr Sci 2008; 325: 371-5.

http://dx.doi.org/10.1016/j.memsci.2008.07.051

[10] Sueyoshi Y, Fukushima C, Yoshikawa M. J Membr Sci 2010; 357: $90-7$.

http://dx.doi.org/10.1016/j.memsci.2010.04.005

[11] Sueyoshi Y, Utsunomiya A, Yoshikawa M, Robertson GP, Guiver MD. J Membr Sci 2012; 401-402: 89-96. http://dx.doi.org/10.1016/j.memsci.2012.01.033

[12] Ikeuchi $Y$, Nakagawa M, Yoshikawa M, Yoshida H, Sakurai S. J Polym Sci Part A Polym Chem 2009; 47:2530-8. http://dx.doi.org/10.1002/pola.23335

[13] Hatanaka M, Nishioka Y, Yoshikawa M. Macromol Chem Phys 2011; 212: 1351-9. http://dx.doi.org/10.1002/macp.201100054

[14] Mizushima H, Yoshikawa M, Robertson GP, Guiver MD. Macromol Mater Eng 2011; 296: 562-7. http://dx.doi.org/10.1002/mame.201000396

[15] Robertson GP, Guiver MD, Bilodeau F, Yoshikawa M. J Polym Sci Part A Polym Chem 2003; 41: 1316-29. http://dx.doi.org/10.1002/pola.10683

[16] Riddick JA, Bunger WB, Sakano TK. Organic solvents. 4th ed. New York: Wiley 1986.
[17] Harwood LA, Claridge TDW. Introduction to organic spectroscopy. Oxford: Oxford University Press 1997.

[18] Mizushima H, Yoshikawa M, Robertson GP, Guiver MD. Eur Polym J 2012; 48: 1717-25. http://dx.doi.org/10.1016/j.eurpolymj.2012.07.003

[19] Walton DJ, Lorimer JP. Polymers. Oxford: Oxford University Press 2000

[20] Mulder M. Basic principles of membrane technology. 2nd ed. Dordrecht: Kluwer Academic Publishers 1996.

[21] Baker RW. Membrane technology and applications. 2nd ed. West Sussex: Wiley 2004.

[22] Kakuchi T, Takaoka T, Yokota K. Polym J 1990; 22: 199-05. http://dx.doi.org/10.1295/polymj.22.199

[23] Masawaki T, Sasai M, Yone S. J Chem Eng Jpn 1992; 25: 33-9.

http://dx.doi.org/10.1252/jcej.25.33

[24] Aoki T, Tomizawa S, Oikawa E. J Membr Sci 1995; 99: 11725.

http://dx.doi.org/10.1016/0376-7388(94)00199-9

[25] Tone S, Masawaki T, Eguchi K. J Membr Sci 1996; 118: 31 40.

http://dx.doi.org/10.1016/0376-7388(96)00071-3

[26] Wang H-D, Chu L-Y, Song H, Yang J-P, Xie R, Yang M. J Membr Sci 2007; 297: 262-70. http://dx.doi.org/10.1016/i.memsci.2007.03.055

[27] Hazarika S. J Membr Sci 2008; 310: 174-83. http://dx.doi.org/10.1016/j.memsci.2007.10.055

[28] Hatanaka M, Nishioka Y, Yoshikawa, M. J Appl Polym Sci in press. 